\title{
Gestión comunitaria durante la pandemia COVID-19 bajo la mirada de la innovación social: estudio de seis casos.
}

\author{
Ana Milena Padilla-Ospina, Ph.D.
}

UNIVERSIDAD DEL VALLE

Javier Humberto Ospina-Holguín, Ph.D.

UNIVERSIDAD DEL VALLE

\section{RESUMEN}

El propósito de este articulo es evidenciar el surgimiento de procesos de innovación social y gestión comunitaria para solucionar problemas sociales de una comunidad en el contexto de la pandemia del COVID-19. A partir de un análisis documental, se recopilaron seis casos, tres colombianos y tres brasileros, que demuestran cómo las comunidades se organizaron para generar ideas innovadoras con el fin de darle solución a un problema común, en este caso la mitigación de los impactos sociales negativos que se han presentado por la pandemia. De los casos documentados se puede concluir que, en época de crisis, la gestión comunitaria permite la generación endógena de estrategias novedosas y efectivas para enfrentar los problemas de la comunidad y que los gobiernos podrían inspirarse en ellas para satisfacer mejor las necesidades sentidas que con estrategias totalmente exógenas.

Palabras clave: innovación social; COVID-19; gestión comunitaria; estrategias endó

\begin{abstract}
The purpose of this article is to demonstrate the emergence of processes of social innovation and community management to solve social problems of a community in the context of the COVID-19 pandemic. Based on a documentary analysis, six cases were collected, three Colombians and three Brazilians, which demonstrate how communities organized themselves to generate innovative ideas in order to solve a common problem, in this case the mitigation of the negative social impacts that have been presented by the pandemic. From the documented cases, it can be concluded that, in times of crisis, community management allows the endogenous generation of innovative and effective strategies to address community problems and that Governments could draw inspiration from them to better meet the needs felt than with totally exogenous strategies.
\end{abstract}

Keywords: social innovation; COVID-19; community management; endogenous strategies 


\section{INTRODUCCIÓN}

I

a innovación social surge como una herramienta que permite la solución de una problemática social que aqueja a una apoyar las actividades de innovación social en sus países (Comisión Europea, 2013; Edmiston, 2015; Fundación COTEC, 2016; Presidencia del consejo de Ministros de Perú, 2013). En este contexto, la innovación social "se refiere a actividades y servicios innovadores que están motivados por el objetivo de satisfacer una necesidad social y que se difunden predominantemente a través de organizaciones cuyos propósitos principales son sociales" (Mulgan, 2006).

Los países latinoamericanos son considerados como la región más desigual del planeta, y existe una creciente brecha entre los ricos y los pobres (Lissardy, 2020). Según un estudio de la CEPAL (2019), la pobreza en la región pasó de un $28 \%$ en el año 2014 a un $31 \%$ en el año 2019 y se estima que 26 millones de personas se encuentran en situación de extrema pobreza. Adicionalmente, el trabajo informal ha aumentado en la región, en detrimento de la calidad laboral y los ingresos personales (CEPAL, 2019, p. 127).

Con la llegada de la pandemia COVID-19, se espera un retroceso del PIB latinoamericano de $-5.3 \%$ según cálculos de la CEPAL (2020), en una situación cada vez más difícil para los gobiernos que deben endeudarse cada vez más con el fin de enfrentar la crisis sanitaria, social y económica. En este contexto surgen iniciativas de los ciudadanos de comunidades vulnerables que permiten sobrellevar los estragos socioeconómicos de la pandemia. El objetivo de este trabajo es documentar casos de gestión comunitaria en Brasil y Colombia a través del proceso de la innovación social del sector público y sus fases (iniciador, co-diseñador y co-implementador).

De esta forma, la primera parte de este documento se concentra en explicar brevemente los alcances de la innovación social para el sector público. En la segunda parte, se expone la situación de la pandemia en Brasil como forma introductoria a tres casos: las costureras de 
las escuelas de samba que confeccionan capas y tapabocas para los hospitales del país, el papel de los carteles/pandillas en el control de la pandemia en las favelas de Rio de Janeiro y cómo la segunda favela más grande de São Paulo se ha preparado mediante la gestión comunitaria para mitigar los efectos de la pandemia.

En la tercera parte del documento, se presenta una introducción al manejo de la pandemia en Colombia, seguido de los tres casos de gestión comunitaria: los trapos rojos como símbolo de la solidaridad, las ollas comunitarias en Cali y la creación de un cubrerrostro a partir de botellas de plástico. El documento finaliza con las conclusiones que se evidencian en cada uno de los casos, vistos bajo los planteamientos de la innovación social.

\section{LA INNOVACIÓN SOCIAL Y LA GESTIÓN COMUNITARIA}

Desde el año 2002 han surgido estudios de la innovación social desde diferentes perspectivas, tales como desde la ciencia política, la administración y los negocios, la sociología y la tecnología. Para Mumford (2002) la innovación social es la generación e implementación de nuevas ideas acerca de la gente y sus interacciones dentro de un sistema social. Por su parte, para Phills, Deiglmeier y Miller (2008) la innovación social se refiere a perseguir una nueva solución a un problema social más efectiva, eficiente y sostenible que las soluciones existentes. Para otros autores, tales como Boons y Lüdeke-Freund (2013), la innovación social es un modelo de negocio relacionado con la creación de valor social.

Moulaert, Martinelli, González y Swyngedouw (2005) consideran que existen cuatro dimensiones de la innovación social: la satisfacción de las necesidades básicas, los cambios en las relaciones sociales con respecto a la gobernanza, el incremento de la capacidad socio-política y el acceso a los recursos. Voorberg, Bekkers y Tummers (2014) hacen una distinción entre lo que se podría considerar Innovación social corporativa y la innovación social del sector público. La innovación social corporativa consiste en la creación de una empresa o el direccionamiento de una empresa que busque co-crear y co-producir un artículo que esté acorde con 
las expectativas de los consumidores, por ejemplo, que un artículo amigable con el medio ambiente que utilice materiales reciclados o que sea orgánico. De esta forma, el consumidor final es quien promueve la creación y la producción del bien (producto o servicio) en colaboración con la compañía (Figura 1).

La innovación social en el sector público está centrada en el ciudadano como actor principal. El ciudadano puede actuar como un iniciador, co-diseñador o co-implementador (Voorberg et al., 2014). Un ciudadano iniciador es aquel que piensa en soluciones innovadoras a los problemas sociales de su comunidad. Un ciudadano co-diseñador es aquel que participa en el proceso de creación de la idea innovadora para darle solución a un problema de la comunidad. El proceso del ciudadano como iniciador y codiseñador se enmarca en una actividad de co-creación que incluye mecanismos como la participación ciudadana, la gobernanza y el consenso con la comunidad. Un ciudadano que co-implementa es un ciudadano que participa en la aplicación de las soluciones a un problema que afecta a la comunidad, que han sido co-diseñadas en conjunto con diversos actores sociales (Ben-Ari, 1990; Voorberg et al., 2014).

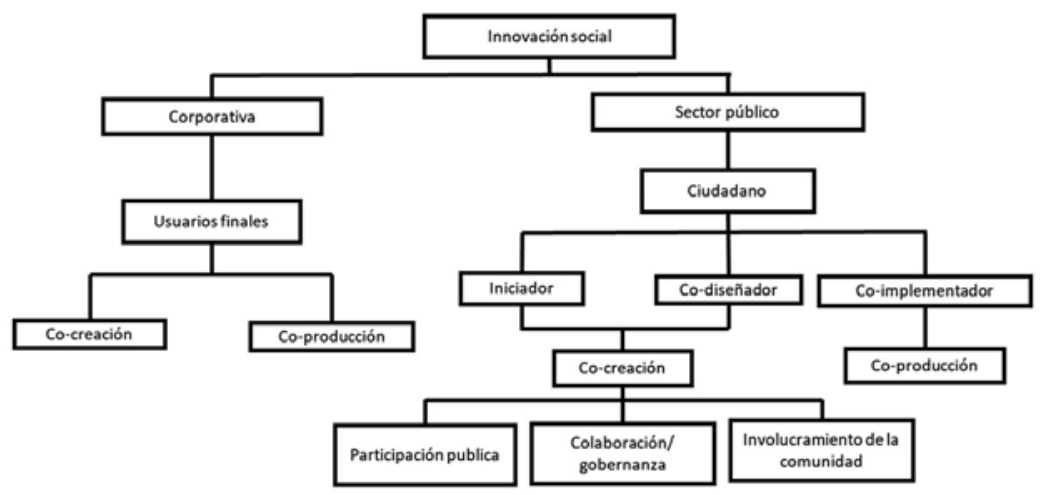

Figura 1. Ramificaciones en el estudio de la Innovación social, (Adaptado de: Voorberg et al., 2014). 
Cabe resaltar que solo en las fases de iniciación y co-diseño se espera que exista un proceso de co-creación, es decir una colaboración para la creación de ideas o estrategias para lograr el objetivo planteado por la comunidad. Esta colaboración en ocasiones se materializa mediante la participación ciudadana, la gobernanza y las reuniones de las comunidades objeto de trabajo. En la fase de co-implementación se recurre a la co-producción, es decir, a la colaboración de los actores involucrados en la materialización de la idea o estrategia que se adopta para la solución del problema de la comunidad (Voorberg, Bekkers, \& Tummers, 2013; Voorberg et al., 2014).

En la década de los cincuenta, las Naciones Unidas define al desarrollo de la comunidad, como un proceso participativo y colaborativo de las personas que pertenecen a una comunidad que tiene como objetivo establecer planes y estrategias para mejorar el nivel de vida y solucionar problemas de la comunidad (Ander-Egg, s/f; Sarduy \& Campos, 2014). Por otra parte, el fenómeno de la organización comunitaria se surge en los Estados Unidos en los años cuarenta, luego se espacio como desarrollo comunitario en Asia y África, para finalmente se desarrolla en América Latina y Europa (Pérez-Díaz, 2016; Sarduy \& Campos, 2014).

Las organizaciones comunitarias son una respuesta de los miembros de la comunidad para trabajar voluntariamente en estrategas de bienestar social de la comunidad, la cual surge a falta de la intervención de los organismos estatales o por que los existentes no suplen las necesidades de la comunidad (Ander-Egg, 2003). El desarrollo que puede lograr una comunidad con la participación y cooperación de sus miembros, permite generar una red social más cohesionada, que se enfoca en los mismos intereses y objetivos para el desarrollo de proyectos sociales, educativos, recreativos y productivos que les permita integrar a todos los miembros de la comunidad (Alonso, Riera, \& Rivero, 2013).

La gestión comunitaria se define como la organización de la comunidad en la realización de una labor ya sea de forma autónoma o en conjunto a proyectos planteados por el gobierno 
y el sector privado ("La Gestión Comunitaria como Concepto", s/f). Iniciativas como la construcción del manual de la gestión Comunitaria en Bogotá, permiten enmarcar este tipo de actividades como parte del desarrollo de una comunidad independiente de su estatus socioeconómico, territorial y cultural (Avella-Bernal, 2004). Así, se puede considerar que la gestión comunitaria se encuentra altamente relacionada con los enfoques de desarrollo comunitario y las organizaciones comunitarias por su componente participativo de los miembros de la comunidad hace la solución de problemas o búsqueda de estrategias para el mejoramiento del bienestar social de la comunidad.

De esta forma, el enlace entre la gestión comunitaria y la innovación social está en que la comunidad misma es la que plantea las ideas y proyectos a desarrollar en su comunidad abordados desde una perspectiva novedosa y que tiene un propósito especifico de solventar unas necesidades detectadas por las mismas personas de la comunidad. El involucramiento de los actores gubernamentales y del sector privado se da, ya sea porque la misma comunidad los invita a participar o porque estos organismos ven en el apoyo de estas iniciativas una forma de crear un vínculo estrecho con estas comunidades, respetando sus decisiones e ideas.

En los casos que se presentan a continuación se puede vislumbrar cómo funciona la innovación social del sector público, donde la comunidad frente a la situación social y sanitaria de la pandemia COVID-19 se ha organizado y generado sus propios planes de mitigación para evitar estragos mayores en sus comunidades. Estas iniciativas surgen por la falta de acción del Estado en la contención del virus, no solo en términos de salud, sino en términos sociales, en un contexto en que muchas personas dependen de trabajos informales y otros más perdieron sus empleos formales. En los ejemplos ofrecidos normalmente una persona actúa como iniciador de la idea y poco a poco se le suman otras personas, instituciones gubernamentales o el sector privado como co-diseñadores de la idea y finalmente existen co-implementadores voluntarios que hacen realidad la idea, en un proceso que se puede considerar en pocas palabras como gestión comunitaria. 


\section{El CODIV-ig en Brasil}

El primer caso de contagio en el territorio brasilero se reportó el 9 de febrero de 2020, por parte de un ciudadano brasilero que llegó de un vuelo proveniente de Lombardía, Italia ("Coronavirus: Brasil confirma el primer caso en América Latina”, 2020). La primer muerte reportada por este virus fue el 17 de marzo de 2020 en la ciudad de São Paulo ("Primera muerte por coronavirus en Brasil: un paciente de 62 años falleció en San Pablo”, 2020). Durante el primer semestre del año 2020, como se aprecia en la Figura 2, se han reportado 59.954 muertes, 1.402 .041 casos confirmados y 790.040 casos recuperados ("Coronavirus/Brasil", 2020). Brasil es el segundo país con más contagios por COVID-19, después de Estados Unidos, y es el primer país latinoamericano con más casos y muertes, seguido de Perú ("Brasil supera los 50.000 muertos por coronavirus", 2020).

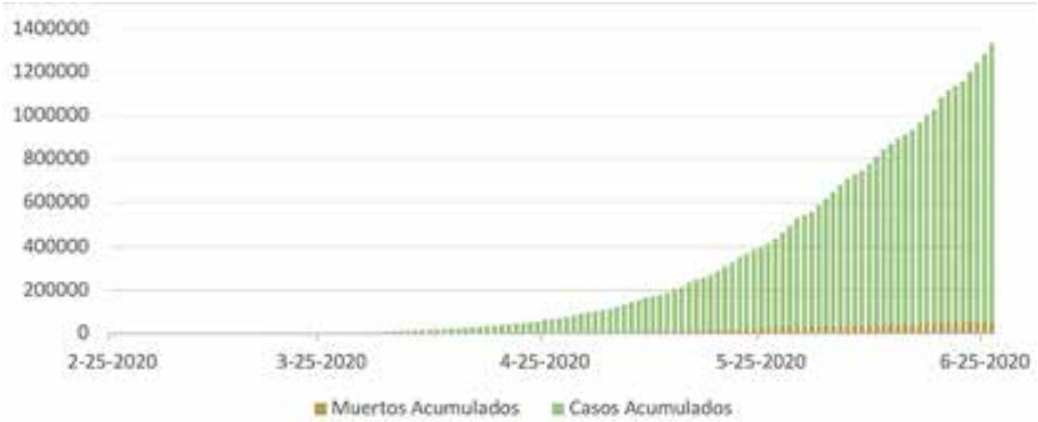

Figura 2. Curva de contagio de COVID-19 en Brasil: número de casos y muertes acumuladas. (Fuente: "Coronavirus/Brasil”, 2020).

Las medidas tomadas por el Gobierno Federal dan inicio el 16 de marzo de 2020 y están enfocadas a mantener la economía, el empleo y salvaguardar a la población de avanzada edad (Ministério da Economia, 2020). El 18 de marzo el Congreso Nacional autoriza recursos para la compra de implementos médicos con cero arancel y declara el Estado de Calamidad (Ministério da Economia, 2020). El 19 de marzo se amplia el monto asignado por el gobierno a la 
pandemia para brindarle a la población desempleada un subsidio (Ministério da Economia, 2020). El 2 de abril se aprueba la Ley 13.982 que autoriza el pago de ayuda de emergencia de $\mathrm{R} \$ 600$ a 18 millones de trabajadores beneficiarios y el 13 de abril se aprueba la distribución de 154.400 mercados básicos para la población indígena (Ministério da Economia, 2020).

El presidente de Brasil, Jair Bolsonaro, se ha enfocado durante la pandemia en mantener abierta la economía del país, en medio de una reducción del PIB del país durante el primer semestre de 1.5\% (Ministério da Economia, 2020). Desde el inicio de la pandemia, el presidente Bolsonaro no le ha dado mayor importancia a contrarrestar los efectos en pérdidas de vidas humanas que trae consigo la pandemia, y así ha alentado, por ejemplo, a sus seguidores a asistir a eventos multitudinarios, no usa tapabocas y no promueve el aislamiento social, esto es, la cuarentena ("Coronavirus en Brasil: 7 errores que llevaron a Brasil a la crítica situación actual”, 2020). En contraste, las ayudas sociales a la población más vulnerable han estado a cargo de líderes sociales, del sector privado y de donaciones de las ONGs que buscan darle un alivio a los 31 millones de habitantes que viven del trabajo informal en Brasil ("Brasil no abona el segundo pago del subsidio a los trabajadores informales por falta de fondos", 2020).

Mientras tanto, los gobernadores de los estados de Sáo Paulo y Rio de Janeiro implementaron medidas de aislamiento social y el cierre del comercio, en contravía de lo planteado por el presidente, lo que ha causado gran confusión entre la población ("Coronavirus en Brasil: 7 errores que llevaron a Brasil a la crítica situación actual", 2020). Otras situaciones, como el cambio constante de Ministros de Salud debido a diferencias con la forma de afrontar la pandemia, ha sido igualmente desconcertantes para los brasileros ("Coronavirus en Brasil: 7 errores que llevaron a Brasil a la crítica situación actual”, 2020).

Las Costureras de las escuelas de SAlsa en Rio de Janeiro En la favela Vila Vintem de Rio de Janeiro, en febrero de cada año, 
las costureras del taller de la escuela de samba Unidos de Padre Miguel trabajan confeccionando el vestuario para el carnaval de Rio de Janeiro de la próxima temporada. Sin embargo, debido a la pandemia, las costureras se han organizado como voluntarias y están trabajando para confeccionar tapabocas para los hospitales y centros de salud de la ciudad desde el 23 de febrero de 2020 (DW Noticias, 2020; "Escolas de samba do Rio ajudam na produção de capotes descartáveis", 2020; Rodrigues \& Biller, 2020). La iniciativa tuvo su origen con el médico William Baracho, quien pertenece a la escuela de samba. Baracho junto con un amigo que trabaja en el sector de la salud se percataron de que en el área de urgencias del hospital más cercano a la comunidad los médicos no contaban con los elementos mínimos de bioseguridad. Entonces ambos le propusieron al presidente de la escuela de samba Unidos de Padre Miguel, Lenílson Leal, que consintiera que las costureras trabajaran como voluntarias confeccionando tapabocas. Ellas aceptaron esta iniciativa y Baracho empezó a conseguir la tela quirúrgica y los patrones para la realización de los elementos de bioseguridad, llegando a producirse 10.000 mascarillas al día ("Fábrica do Samba produz máscaras para doação à Prefeitura", 2020; Rodrigues \& Biller, 2020).

A esta labor se sumó también la escuela de samba Vila Isabel, cuyas costureras también están confeccionando capas médicas desechables para los médicos de urgencias ("Escolas de samba do Rio ajudam na produçáo de capotes descartáveis", 2020; Rodrigues \& Biller, 2020). Hoy en día, su labor está siendo apoyada por RioSaúde, una empresa que distribuye elementos médicos, y por el Estado de Rio de Janeiro, que les brinda gel antibacterial, tapabocas, tela e hilos a las costureras y se encarga de la distribución de los elementos confeccionados a los hospitales del país (Noguera-Montoya, 2020). Se estima que en el Hospital Municipal Ronaldo Gazolla, ubicado en el barrio de Acarí al norte de Río, se utilizan entre 2.000 capas y tapabocas al día (Noguera-Montoya, 2020).

Los voluntarios manifiestan que realizan esta labor por amor a su ciudad y para ayudar a la gente, un espíritu de solidaridad que 
surge de ver cómo muchos cercanos a su comunidad se han visto afectados por el virus y cómo los médicos y hospitales se han visto en dificultades para atender a los contagiados por el COVID-19. A la fecha, el Sambodromo de Río sirve de centro de acopio de donaciones y entrega de mercados para las personas más vulnerables de las favelas de Río (DW Noticias, 2020).

En mayo de 2020 la Escuela de Samba ha realizado constantemente jornadas de entrega de tapabocas y atención médica gratuita para aquellos habitantes de la Favela Vila Vintém que tengan síntomas del COVID-19 y no tengan recursos para asistir a centros asistenciales ("Unidos de Padre Miguel oferece atendimento médico e máscaras para a comunidade", 2020)

\section{El accionar de los carteles de Rio ante el COVID-i 9}

Con la llegada del virus COVID-19 a Río de Janeiro, la población de las favelas ha tenido que lidiar por su cuenta con la enfermedad, ya que el Estado ha brindado pocas ayudas sociales y no ha habido una política clara para contener la pandemia en medio de la contradicción entre los gobernadores y el presidente. Aquellas favelas que se encuentran al mando de poderosas pandillas de narcotraficantes, como la Favela Cidade de Deus ubicada en la zona oeste de Río de Janeiro, al día de hoy están controladas por estas mismas pandillas, que son quienes imponen entre los miembros de su comunidad el uso del tapabocas, el cumplimiento de las medidas de distanciamiento social, además de los toques de queda y la entrega de mercados a las familias más necesitadas (Blois, 2020; Paton-Walsh, Shelley, Bonnett, \& Fortuna, 2020).

Muchas de estas favelas son territorio inaccesible para la policía, a menos que realicen una redada, y están fuera del alcance de la asistencia sanitaria estatal debido al control que ejercen las pandillas que controlan el microtráfico de estupefacientes en la ciudad. Según los pandilleros, "le temen al virus más no al presidente Jair Bolsonaro", quien ha jurado acabar con las pandillas del Estado de Río de Janeiro. Así, son los pandilleros quienes diariamente le hacen llegar a su comunidad alimentos, gel antibacterial y medicinas. La 
situación es grave, ya que debido al hacinamiento en las viviendas y a la gran cantidad de personas que trabajan en la informalidad, ha habido muchos contagios y muertos en la zona, tanto así que la misma comunidad ayuda para recolectar dinero para los entierros (Paton-Walsh et al., 2020).

Los médicos que viven en la comunidad ayudan en ocasiones de forma voluntaria a sus vecinos, pero las personas que no cuentan con recursos financieros muchas veces no obtienen la asistencia médica requerida (Paton-Walsh et al., 2020). La presión para estas pandillas es grande, patrullan las calles de las favelas fuertemente armados imponiendo el toque de queda que inicia a las 8:00 p.m., quienes no lo cumplan pueden sufrir consecuencias violentas. En la favela Rocinha y Vidigal, por ejemplo, los restaurantes y tiendas cierran temprano, no colocan sillas y mesas afuera de sus establecimientos por órdenes de las pandillas y está prohibida la entrada a turistas (Barsetti, 2020). Sin embargo, a pesar de su labor, los pandilleros siguen siendo blancos para los policías, ya que Bolsonaro ha autorizado disparar a matar cuando se hacen redadas en las favelas (Blois, 2020; Paton-Walsh et al., 2020).

Las iniciativas de estos grupos delincuenciales surgen de la necesidad de proteger a su propia comunidad del efecto mortal de la pandemia. Su accionar ha cambiado de traficar drogas ilícitas a ser proveedores de alimentos y medicinas y a mantener el orden social, pues las pandillas son conscientes de que si la comunidad no se cuida, no tendrán un futuro como organización delincuencial.

Paraisopolis y las medidas de mitigación contra el COVID-I9 Paraisópolis es la segunda favela más grande de São Paulo, con más de 100.000 habitantes. Esta Favela está compuesta por 21.000 hogares en 800.000 metros cuadrados (Sims, 2020). Olvidados por el Estado, la comunidad ha tomado cartas en el asunto para mitigar el COVID-19 en su territorio (Drable, 2020). Las calles en la favela son estrechas y llenas de escaleras, y los servicios asistenciales no se atreven a ir a atender a los pobladores de la favela por las condiciones de violencia. Ante la ausencia del Estado, la comunidad 
ha decidido organizarse y pagar de su bolsillo a tres ambulancias (una con UCI móvil) y a un equipo médico conformado por dos médicos, dos enfermeras y tres paramédicos que están a disposición de la comunidad las 24 horas al día, ya que se mudaron a vivir en la favela en una casa provista por la misma comunidad (Drable, 2020; Paiva, 2020b).

Gracias a la gestión la Asociación de Residentes, la Asociación de Mujeres de Paraisópolis y el G10 de las Favelas, que reúnen a los líderes sociales de las 10 favelas más grandes del país, también se creó el programa de ayuda para la favela de Paraisópolis (Paiva, 2020b). Entre los líderes se eligieron 420 voluntarios que están encargados de vigilar cada uno 50 casas en la favela. Esta vigilancia consiste en visitar a cada una de las casas que les fueron asignadas para identificar en los hogares si tienen síntomas de CODIV-19 o si requieren asistencia médica por otras enfermedades. Estos voluntarios se comunican por WhatsApp con los líderes encargados de coordinar los equipos médicos contratados (Drable, 2020). También identifican la situación financiera de cada familia con el fin de hacerles llegar ayuda de alimentos y medicamentos si los requieren (Paiva, 2020b). Los fondos con los cuales se llevan a cabo estas iniciativas surgen de donaciones recolectadas en línea y del trabajo voluntario de la comunidad (Sims, 2020).

Además, a pesar de que el gobierno de la ciudad de Sáo Paulo está distribuyendo alimentos y tanques de agua a la favela, la propia comunidad ha organizado su equipo de 15 mujeres que tiene la misión de repartir 6.000 almuerzos gratis al día, cifra que se espera aumente hasta los 10.000 almuerzos al día (Langlois, 2020; Paiva, 2020b; Sims, 2020). Adicionalmente, las mujeres pertenecientes a la Asociación de Mujeres de Paraisópolis confeccionan 50.000 tapabocas diariamente que se distribuyen a toda la comunidad (Meneses-Sánchez, 2020).

Otra forma de prevenir los contagios de COVID-19 en la favela fue la adecuación de dos escuelas públicas de Paraisópolis (las Escuelas Etelvina de Goés Marcucci y Maria Zilda Gamba Natel) que sirven de albergue para que hasta 500 habitantes de la comunidad 
que hayan sido diagnosticados como positivos para COVID-19 puedan aislarse en sus instalaciones, evitando sucesivos contagios en sus propias casas (Paiva, 2020a). En las escuelas no hay atención médica como tal, pero si un paciente se agrava hay una ambulancia para su traslado a un hospital. El propósito de la adecuación de las escuelas es que los infectados pasen el tiempo de recuperación de la enfermedad aislados de sus familias, que puedan acceder a una buena alimentación, y a servicios sanitarios en un espacio para reposar mientras se recuperan. Esta iniciativa ha surgido debido al hacinamiento extremo que existe en las casas de la favela, donde dos o más familias comparten casas de dos o tres habitaciones con un solo lavamanos (Langlois, 2020; Sims, 2020). La iniciativa ha recibido también financiación de la empresa privada (Paiva, 2020a).

Según comunicación personal (Rocha, 2020) al 21 de octubre del 2020, la Favela de Paraisópolis cuenta solo con una ambulancia, los espacios de aislamiento para pacientes positivos COVID-19 han cerrado, los almuerzos comunitarios los disminuyeron a la mitad dado que se disminuyeron las donaciones que recolectaban los líderes de la Favela. La pobreza en la zona ha incrementado considerablemente por el desempleo y falta de ayudas estatales. "El gobierno anuncio una tarjeta de alimentación por 200 Reales, pero yo nunca lo recibí, muchos en mi comunidad no recibimos nada de ayudas a pesar de la situación"(Comunicación personal: Rocha, 2020)

Hoy en día la comunidad de la Favela está más relajada en el uso de elementos de bioseguridad, las personas salen a los bares (que nunca cerraron durante la cuarentena) y a la calle sin tapabocas, no hay distanciamiento social, solo algunos establecimientos solicitan el uso de mascara para entrar, pero poco a poco la comunidad se ha ido relajando con las medidas de seguridad (Comunicación personal: Rocha, 2020).

\section{El COVID-i 9 en Colombia}

En Colombia el primer caso de coronavirus se reportó el 6 de marzo de 2020 proveniente de una ciudadana que retornaba de un viaje de 
Milán, Italia (Ministerio de Salud, 2020). Según el DANE, la primera muerte sospechosa por el COVID-19 ocurrió el 15 de febrero de 2020 y la primera muerte confirmada por COVID-19 ocurrió el 26 de febrero de 2020 (DANE, 2020b, p. 27). Adicionalmente, se estima que durante el primer trimestre del ańo 2020 murieron en Colombia 30 personas por cuenta del coronavirus: el $70 \%$ de los fallecidos tenían más de 55 años y el 60\% eran hombres (DANE, 2020b, pp. 27-29). En la Figura 3 se puede observar la evolución de casos sospechosos, confirmados y de influenza/neumonía reportados en Colombia en el primer trimestre del año 2020.

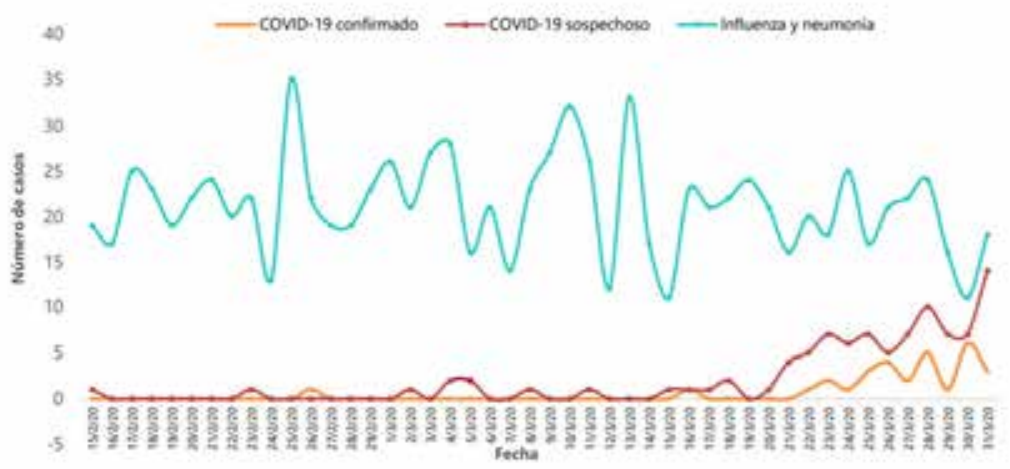

Figura 3. Defunciones por día, según número de casos COVID-19 confirmados, sospechosos, neumonía e influenza. (Fuente: DANE, 2020b, p. 27).

Al 26 de junio del 2020, Colombia cuenta con 84.442 casos positivos, de los cuales 34.937 se han recuperado y 2.811 han fallecido (Figura 4) (Instituto Nacional de Salud, 2020). Las ciudades más afectadas por la pandemia han sido Bogotá D.C. (25.540 casos), Barranquilla (10.922 casos), Cartagena (7.330 casos), Cali (6.631 casos), Leticia (2.132 casos) y Buenaventura (1.356 casos) (Instituto Nacional de Salud, 2020). 


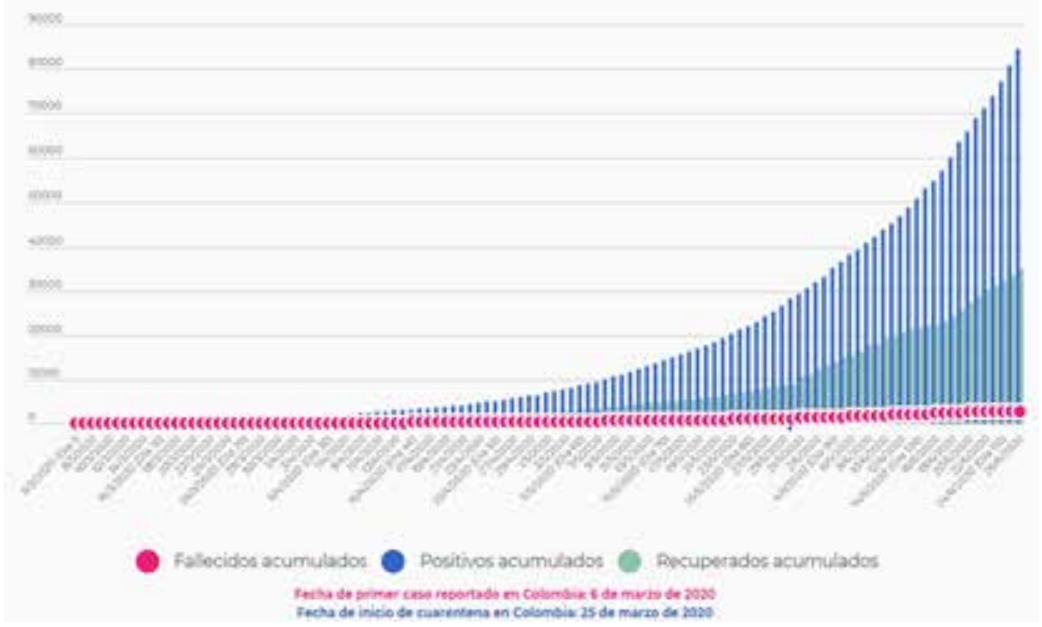

Figura 4. Curva de Contagios, fallecidos y recuperados por COVID-19 en Colombia. (Fuente: Instituto Nacional de Salud, 2020).

Las medidas adoptadas por el Gobierno nacional para contrarrestar el COVID-19 estuvieron enfocadas en la cuarentena total que inició el 25 de marzo de 2020 y que se ha venido flexibilizando desde del 1 de junio de 2020 gracias una reactivación escalonada de los sectores económicos del país. A continuación, se presenta una cronología de algunos de los decretos más importantes expedidos por el Gobierno central:

Decreto 457 del 23 de marzo de 2020 que establece las pautas del aislamiento obligatorio preventivo desde el 25 de marzo hasta el 13 de abril. Se establecen igualmente 34 excepciones para salir, tales como el abastecimiento de comida, medicinas y el uso de servicios bancarios para una persona del núcleo familiar. En varias ciudades del país, los alcaldes decidieron adoptar medidas como el pico y cédula, según el cual los días en que los habitantes pueden salir dependen del último número de su cédula, o el pico y género, según el cual los días en que los habitantes pueden salir dependen del género (Moreno, 2020). 
Decreto 531 del 8 de abril de 2020 que establece la ampliación del aislamiento preventivo obligatorio o cuarentena nacional desde el 13 de abril hasta el 27 de abril. Se establecen asimismo 35 excepciones, entre las que se encuentran: asistencia y prestación de servicios de salud; adquisición de bienes de primera necesidad, desplazamiento a servicios bancarios y servicios notariales; asistencia y cuidado a nińos, niñas, adolescentes, personas mayores de 70 años, personas con discapacidad y enfermos con tratamientos especiales que requieren asistencia de personal capacitado; las labores de las misiones médicas de la Organización Panamericana de la Salud (OPS) y de organismos internacionales humanitarios y de salud; la prestación de los servicios profesionales, administrativos, operativos y técnicos de salud públicos y privados; la cadena de producción, abastecimiento, almacenamiento, transporte, comercialización y distribución de medicamentos, productos de limpieza, desinfección y aseo personal para hogares y hospitales; las actividades relacionadas con servicios de emergencia, incluidas las emergencias veterinarias, y los servicios funerarios; la cadena de producción, abastecimiento, almacenamiento, transporte, comercialización y distribución de insumos para producir bienes de primera necesidad; la comercialización presencial de productos de primera necesidad en mercados de abastos, bodegas, mercados, supermercados mayoristas y minoristas y mercados al detal en establecimientos y locales comerciales a nivel nacional, quienes podrán comercializar sus productos mediante plataformas de comercio electrónico y/o para entrega a domicilio; las actividades de los servidores públicos y contratistas del Estado que sean estrictamente necesarias para prevenir, mitigar y atender la emergencia sanitaria por causa del coronavirus covid-19, para garantizar el funcionamiento de los servicios indispensables del Estado. De la misma manera, están permitidas las actividades de las Fuerzas Militares, la Policía Nacional y organismos de seguridad del Estado, así como de la industria militar y de defensa; las actividades de los puertos de servicio público y privado, exclusivamente para el transporte de carga; la ejecución de obras de infraestructura de transporte y obra pública, así como 
la cadena de suministros de materiales e insumos relacionados con la ejecución de las mismas; el funcionamiento de la prestación de los servicios de vigilancia y seguridad privada, los servicios carcelarios y penitenciarios y de empresas que prestan el servicio de limpieza y aseo en edificaciones públicas y zonas comunes de edificaciones; las actividades necesarias para garantizar la operación, mantenimiento, almacenamiento y abastecimiento de la prestación de servicios públicos de acueducto, alcantarillado, energía eléctrica, alumbrado público, aseo; el funcionamiento de los servicios postales, de mensajería, radio, televisión, prensa y distribución de los medios de comunicación; el abastecimiento y distribución de bienes de primera necesidad, en virtud de programas sociales del Estado y de personas privadas; las actividades de los operadores de pagos de salarios, honorarios, pensiones, prestaciones económicas públicos y privados; y el desplazamiento estrictamente necesario del personal directivo y docente de las instituciones educativas públicas y privadas, para prevenir, mitigar y atender la emergencia sanitaria por causa del coronavirus covid-19 (Ministerio del Interior, 2020).

Decreto 493 de 24 de abril del 2020 que extiende el aislamiento preventivo obligatorio del 27 de abril al 11 de mayo. En este decreto de adicionan seis nuevas excepciones a la medida, entre las que se encuentran: las actividades relacionadas con el sector de la construcción; la industria manufacturera; la comercialización de accesorios y repuestos de bicicletas; la operación de parqueaderos públicos; la operación de juegos de suerte y azar, apuesta permanente, chance y lotería; la reapertura de comisarías de familia e inspecciones de policía; las actividades relacionadas con los avalúos y estudios de títulos para la constitución de garantías ante entidades vigiladas por la Superintendencia Financiera; y la autorización de la realización de actividad física una hora diaria a las personas con edades entre 18 y 60 años, a un kilómetro de su domicilio.

Decreto 636 de 6 de mayo de 2020 que extiende el aislamiento preventivo obligatorio del 11 de mayo al 25 de mayo.

Decreto 689 del 22 de mayo de 2020 que amplía el aislamiento preventivo del 25 de mayo al 31 de mayo de 2020. 
Decreto 749 del 28 de mayo de 2020 que amplía el aislamiento preventivo obligatorio del 1 de junio al 1 de julio. Gracias a este decreto se iniciaron pilotos de reapertura de centro comerciales, restaurantes, gimnasios, peluquerías, museos y bibliotecas para su reapertura el 1 de julio, con las condiciones de bioseguridad impuestas por el Gobierno. Entre ellas están no superar en espacios comerciales un aforo del 30\%. Cabe resaltar que los mayores de 70 años no pueden salir de sus hogares hasta el 31 de agosto de 2020, debido a que la edad más propensa a fallecer en caso de adquirir el COVID-19 (Ministerio del Interior, 2020).

Dentro de las medidas sociales tomadas por el Gobierno está el ingreso solidario, que tiene como objetivo entregarles a las familias en condición de pobreza y vulnerabilidad económica que no reciben ayudas de los programas sociales Familias en Acción, Jóvenes en Acción, Colombia Mayor y Devolución del IVA, un subsidio por $\$ 160.000$ pesos colombianos mensuales para colaborarles con su sostenimiento. Adicionalmente, el Gobierno, mediante las gobernaciones y alcaldías, ha entregado mercados solidarios a las familias colombianas. Se presentaron además lineamientos para el trabajo en casa que incluyen el destino del auxilio de transporte como auxilio de conectividad y se estableció un subsidio del desempleo para las personas que han estado inscritas a una caja de compensación en los últimos seis meses ("COVID-19 en Colombia: medidas tomadas por el Gobierno”, 2020).

Adicionalmente, se estableció la prohibición a los desalojos y el congelamiento de los cánones de arrendamiento, además de la exención del IVA de los planes post-pago de celulares y se definió que no se podrían suspender los servicios de telefonía móvil durante la emergencia ("COVID-19 en Colombia: medidas tomadas por el Gobierno”, 2020).

Finalmente, El Ministerio de Salud y protección social se Colombia publica en marzo de 2020, un libreo con los lineamientos, orientaciones y protocolos para contrarrestar el COVID-19 en el País (Ministerio de Salud y Protección Social, 2020). Dentro de dicho documento se encuentra un apartado donde se establecen 
las medidas de prevención en el entorno comunitario en la cual se recomienda: generar mecanismos de comunicación no presencial con los miembros de la comunidad con discapacidades y adultos mayores que requieran apoyo, establecer medios de apoyo virtuales a través de mensajería instantánea o redes sociales para los miembros de la comunidad, definir redes de apoyo para la identificación de casos de contagio y seguimiento de estos dentro de la comunidad, establecer medidas que permita que los miembros de la comunidad comprendan y pongan en uso los medios de bioseguridad para evitar contagios(Ministerio de Salud y Protección Social, 2020). De esta forma, este documento constituye una clara guía para los líderes sociales y miembros de las juntas de acción comunal puedan desarrollar planes de acción en búsqueda de evitar el aumento de casos de contagio y muertes por el COVID-19.

\section{LOS TRAPOS ROJOS}

Desde el inicio del aislamiento preventivo obligatorio en Colombia se instó a las familias que tuvieran necesidades, ya sea por perder el empleo sus miembros o por su condición de vulnerabilidad, a izar un pedazo de tela rojo como símbolo de necesidad de ayuda. Según un artículo de la Radio Nacional de Colombia, esta iniciativa surgió del alcalde de Soacha (Cundinamarca), quien sugirió a sus pobladores izar un trapo rojo en la ventana en aquellas viviendas que consideraban que necesitaban alimentos para mitigar el hambre, buscando que los vecinos y el mismo Gobierno los visibilizara para que así les hicieran llegar las ayudas de manera inmediata (Hernández, 2020). En algunas ciudades, los vecinos se han ayudado entre ellos, ya sea entregando una libra de arroz o preguntándole al vecino qué necesita como en el caso de Ruth Grisales de Bogotá, quien tomó la decisión de colocar el trapo rojo en su casa dado que perdió su empleo y necesitaba alimentar a su hijo pequeño, y que gracias a la solidaridad de sus vecinos tuvo con que alimentarse diariamente ("QQué significa un trapo rojo en la ventana en tiempos del coronavirus?”, 2020).

De esta forma, al colocar el trapo rojo en la ventana, las familias 
dan a conocer que necesitan ayuda para alimentar a su familia y los hace visible ante una posible entrega de los mercados solidarios que se reparten en el país. Al inicio del aislamiento preventivo obligatorio muchos de los barrios con trapos rojos recibían ayuda de la misma comunidad, pero a medida que la cuarentena se ha prolongado han surgido más viviendas con trapos rojos, lo que ha causado que las familias salgan a protestar buscando que los gobiernos locales les ayuden (Melgarejo, 2020). Por esto, algunos analistas consideran que el trapo rojo es una señal de protesta sobre la desigualdad social que se vive en el país: por ejemplo, según fuentes del DANE el $46,7 \%$ de la población en el trimestre de diciembre de 2019 a febrero de 2020 se desempeñaba en trabajos informales (DANE, 2020a).

Incluso en algunos barrios de estratos 3, 4 y 5 se han observado los trapos rojos en las ventanas, lo que evidencia la existencia de una pobreza oculta en algunas ciudades del país. La pobreza oculta se refiere a familias que viven en estratos socioeconómicos medios o altos pero a quienes, por sus ingresos, no les alcanza para vivir en este tipo de estratos socioeconómicos. Según un reportaje de El Espectador, este fenómeno ocurre por dos razones: cuando la familia en algún momento tuvo una bonanza económica en su vida pero en la actualidad no cuenta con suficientes ingresos (como por ejemplo, puede ser el caso de los jubilados) o cuando se heredan propiedades en lugares costosos de la ciudad y no se cuenta con recursos para su sostenimiento (García-Altamar, 2020; Torres, Morales, \& Vargas, 2011). Aunque este fenómeno se ha estudiado ampliamente en Bogotá, recientemente con la pandemia se evidenció que en ciudades como en Bucaramanga existen más de 300 familias en condición de pobreza oculta que viven en estratos 4, 5 y 6 y que recibieron mercados solidarios por la alcaldía de este municipio (Quintero, 2020).

En Cali, se han visto trapos rojos en el Distrito de Aguablanca, los Farallones de Cali, en los barrios del Centro del Cali como San Bosco y hasta en barrios de tradición como Vipasa. Sin embargo, se han presentado hechos bochornosos como las famosas fiestas masivas en los barrios del oriente de Cali en las cuales se observan 
trapos rojos en algunas casas ("Tiros al aire y rumba en una casa con el 'trapito rojo' en Cali”, 2020; “Una fiesta de más de 500 personas fue descubierta en el oriente de Cali”, 2020).

En suma, y a pesar de estos hechos, los trapos rojos se han convertido en un símbolo de esperanza para muchos colombianos que necesitan de la solidaridad de sus vecinos y del Gobierno para poder sobrellevar de una mejor manera el aislamiento preventivo obligatorio, aislamiento que en muchos casos no les permite salir a buscar el sustento para sus familias, ya por las restricciones de la cuarentena, ya por la falta de empleo.

\section{LAS Ollas COMUNitarias de CALI}

Aunque algunos barrios con familias vulnerables de Cali han recibido ayudas del Gobierno municipal, de fundaciones y de la empresa privada, otros barrios, sobre todo en el oriente de Cali, han desarrollado sus propias estrategias comunitarias para lograr que les rinda lo que mercan y que todos los habitantes se puedan beneficiar sin ser excluidos. De esta manera, han surgido las "ollas comunitarias" como una alternativa para mitigar el hambre en barrios de la ciudad como Potrero Grande. En este barrio, por ejemplo, voluntarios de la parroquia San Cirilo de Jerusalén se reúnen diariamente para realizar 430 almuerzos para las personas de su comunidad. Estas iniciativas han surgido de los líderes sociales y de las juntas de acción comunal de algunos de los barrios más vulnerables de la ciudad y han recibido el apoyo de la Arquidiócesis de Cali y la financiación de la Secretaría de Bienestar Social de Cali (Cruz-Hoyos, 2020b), entidades que apoyan a 243 ollas comunitarias que benefician a 130.000 personas en la ciudad.

En el barrio Potrero Grande, por ejemplo, de acuerdo con datos recolectados por los mismos líderes comunitarios, se estima que el $67 \%$ de los habitantes vive del "rebusque" en trabajos informales. Considerando el contexto que experimentan sus habitantes a cuentas de la pandemia, donde miles de personas han perdido sus empleos, otras no pueden salir a trabajar en sus oficios informales y otras cuantas no contaban con empleo previo a la pandemia, los líderes 
sociales han trabajado en equipo en la búsqueda de una solución para satisfacer la necesidad alimenticia de su comunidad. En este barrio en particular, además de promoverse la iniciativa de las ollas comunitarias, se ha buscado apoyo de instituciones religiosas, ONGs y organismos municipales (Cruz-Hoyos, 2020b; "Cuatro líderes sociales que son luz de esperanza durante la crisis del Covid-19", 2020). Algunos de los líderes afirman que el esfuerzo se hace con la convicción de hacer el bien a la comunidad y de permitir que estas zonas de la ciudad obtengan unas mejores oportunidades y que no sean estigmatizadas por el resto de la ciudad ("Cuatro líderes sociales que son luz de esperanza durante la crisis del Covid-19”, 2020).

De esta manera, las ollas comunitarias han conformado un tejido social entorno a la alimentación de la comunidad, donde los voluntarios en la cocina asumen sus funciones desde muy temprano en la mañana para cumplirle a su comunidad con un almuerzo saludable, mientras que los líderes sociales se encargan de planificar la entrega de los almuerzos organizando las filas, recordándole a la comunidad de los autocuidados para evitar la propagación del virus y recolectado los $\$ 500$ pesos individuales que sirven para completar los ingredientes, tales como los condimentos (Cruz-Hoyos, 2020b).

En el caso de los barrios de Floralia, Puerto Mallarino y el Jarillón de Floralia, la comunidad ha recibido mercados semanales de parte de la alcaldía de Santiago de Cali, la Fundación Banco de Alimentos y la iniciativa de los lideres sociales de la zona y los trabajadores sociales de la secretaria de bienestar social de la alcaldía de Cali organizan ollas comunitarias de lunes a viernes que benefician a comunidades migrantes de Venezuela, adultos mayores y madres comunitarias (Comunicación Personal: Tunubala, 2020).

Las Caretas de protección elaboradas Con Recipientes PET Desde que inició la pandemia, la creatividad y la innovación han prosperado. Iniciativas como la creación de ventiladores de bajo costo por parte de ingenieros y médicos de la Universidad de Antioquia ("Respiradores artificiales nacionales están listos para salvar las vidas de pacientes con covid-19”, 2020), la creación de un lavamanos 
portátil por parte de ingenieros mecánicos de la Universidad del Valle ("Un lavamanos portátil para enfrentar la pandemia", 2020), la producción de gel antibacterial por la Universidad Nacional ("UNAL produce gel antibacterial por la emergencia sanitaria", 2020) y la creación de un dispensador de gel antibacterial por parte de la Universidad del Magdalena ("En Santa Marta fabrican dispensador de gel antibacterial con materiales de construcción", 2020), al igual que las cabinas de cambio de ropa para personal médico de la Universidad Nacional ("Diseñan cabinas para que personal médico se cambie sin contaminar", 2020) destacan por su creatividad e innovación ${ }^{1}$.

El sector productivo no se queda atrás. En Cali, una empresa productora de plásticos ingenió la forma de crear una careta protectora a partir de una botella PET (Cruz-Hoyos, 2020a). Con un costo de producción de $\$ 1.800$ pesos, este producto tiene un alto potencial de ventas no solo para su uso en medios clínicos, sino también por la comunidad en general como medio de protección adicional en contra del Coronavirus (Cruz-Hoyos, 2020a). La empresa productora no ha patentado este invento, ya que considera que es un derecho humano el poder compartir ideas innovadoras que ayuden a mitigar el virus y que permitan que la sociedad se inserte a la nueva normalidad que se vivirá tras la cuarentena (CruzHoyos, 2020a).

Iniciativas como esta buscan generar soluciones frente a un problema identificado, pensando en aspectos como la producción a bajo costo y el uso de materiales fáciles de obtener. Lo anterior demuestra que las empresas no siempre tienen únicamente un fin de lucro: en este caso se creó un producto que es de libre licencia para su producción, lo que permitirá que otros países y empresas que tengan los materiales disponibles puedan beneficiarse de este invento. De hecho, la embotelladora de Coca-Cola en Leticia está realizando estas mascarillas para el personal médico de la región del Amazonas (Cruz-Hoyos, 2020a). 


\section{Conclusiones}

Desde los planteamientos de la innovación social en el sector público se puede explicar cómo surge espontáneamente la gestión comunitaria frente a situaciones como la pandemia del COVID-19. El presente trabajo presenta seis casos de estudio, tres de Brasil y tres de Colombia, que ilustran cómo diferentes actores civiles pueden llegar a generar iniciativas en búsqueda de una solución a los problemas que afectan a una comunidad.

En ocasiones las nuevas iniciativas comienzan con una idea de un individuo que puede ser un líder social, un miembro de la comunidad, un empresario y hasta una persona inmersa en la delincuencia que funge el rol de iniciador de la idea. Una vez planteada la idea a la comunidad, se integran a ella otros actores que co-diseńan la estrategia para llevar a cabo la iniciativa o que coimplementan la idea con la ayuda de miembros de la comunidad, de instituciones del Gobierno, de ONGs o del sector privado.

Con la llegada de la Pandemia de COVID-19, países como Brasil se han visto muy afectados por la ausencia de políticas sociales de apoyo que emanen del Gobierno. Este vacío en las políticas sociales ha dejado desamparadas a comunidades vulnerables en las que se ha gestado como respuesta nuevas iniciativas para la supervivencia, por ejemplo, en las favelas más grandes del país donde el Estado y la ley no llegan. En el caso colombiano, a pesar de la inversión social que se ha realizado en la repartición de mercados y en el ingreso solidario, ha quedado en evidencia la enorme desigualdad social que se vive en el país, donde una gran parte de la fuerza de trabajo es informal y no cuenta con la estabilidad suficiente para sobrevivir a situaciones que ponen en peligro el frágil equilibrio económico de "la subsistencia del rebusque”, además de existir problemas de distribución de agua potable, hacinamiento en las viviendas, bajos ingresos económicos por familia y dificultad para acceder al servicio médico. Más allá de eso, en Colombia también se ha hecho evidente incluso el fenómeno de "la pobreza oculta" en estratos socioeconómicos medios, pobreza oculta que se ha agravado debido a la pandemia.

La innovación social que ha surgido espontáneamente en estas 
situaciones de tensión social demuestra cómo el interés particular se puede transformar en un interés colectivo, donde la misma comunidad busca las opciones de solución frente a la problemática que los aqueja. Hoy en día, esta problemática se plantea en términos de cómo sobrevivir ante la pandemia de un virus letal, pero más adelante podría girar alrededor de otras problemáticas.

Finalmente, los casos presentados son una forma de llamado a los gobiernos para que junto con las comunidades vulnerables detecten cuáles son las necesidades existentes y puedan brindar una ayuda focalizada específicamente a estas, ya que muchas veces lo que el Gobierno plantea no necesariamente es lo que la comunidad realmente necesita. De acuerdo con el rol activo que las comunidades han demostrado poder tomar, se debe escuchar más a las comunidades y tener mayor cercanía con los líderes sociales para brindarles las herramientas y los recursos que les permita generar iniciativas para disminuir los problemas sociales que los aquejan, en lugar de recurrir a soluciones generalizantes y descontextualizadas que se imponen como forma de aculturación.

\section{Referencias}

¿Qué significa un trapo rojo en la ventana en tiempos del coronavirus? (20 de abril de 2020). El Heraldo. Recuperado de https://www. heraldo.es/noticias/sociedad/2020/04/20/que-significa-untrapo-rojo-en-la-ventana-en-tiempos-del-coronavirus-1370673. html

ALONSO, J., RIERA, C. M., \& RIVERO, R. (2013). Fundamentos conceptuales y metodológicos del autodesarrollo comunitario como alternativa emancipadora. CD del XI Taller Internacional de Comunidades; historia y desarrollo. Santa Clara.

ANDER-EGG, E. (2003). Metodología y práctica del desarrollo de la comunidad. Buenos Aires: Argentina: Grupo Editorial Lumen.

ANDER-EGG, E. (s.f). Conceptos de comunidad y desarrollo de la comunidad. En Selección de lecturas sobre trabajo social comunitario (pp. 10-14). Curso de Formación de Trabajadores Sociales. Centro gráfico de Villa Clara. 
AVELLA-BERNAL, L. (2004). Manual de Gestión comunitaria. En Camara de Comercio de Bogotá.

BARSETTI, S. (19 de marzo de 2020). Coronavírus: Tráfico proíbe turistas em favelas do Rio. Terra. Recuperado de https://www. terra.com.br/noticias/coronavirus/coronavirus-trafico-proibeturistas-em-favelas-do-rio,fe51c0a4cb56352a96bda95e0acd642 amrqlvjve.html

BEN-ARI, E. (1990). A bureaucrat in every Japanese kitchen? On cultural assumptions and coproduction. Administration \& Society, 21(4), 472-492. https://doi. org/10.1177/009539979002100405

BLOIS, C. (24 de marzo de 2020). Tráfico impóe toque de recolher em favelas do Rio em meio a crise do corona. Noticias UOL. Recuperado de: https://noticias.uol.com.br/cotidiano/ultimasnoticias/2020/03/24/coronavirus-faccoes-do-trafico-impoemtoque-de-recolher-em-favelas-do-rj.htm

BOONS, F., \& LÜDEKE-FREUND, F. (2013). Business models for sustainable innovation: State-of-the-art and steps towards a research agenda. En Journal of Cleaner Production (Vol. 45). https://doi.org/10.1016/j.jclepro.2012.07.007

Brasil no abona el segundo pago del subsidio a los trabajadores informales por falta de fondos. (23 de abril de 2020). Europa Press. Recuperado de https://www.europapress.es/internacional/ noticia-brasil-no-abona-segundo-pago-subsidio-trabajadoresinformales-falta-fondos-20200423065744.html

Brasil supera los 50.000 muertos por coronavirus. (22 de junio de 2020). El tiempo. Recuperado de https:/www.eltiempo.com/ mundo/latinoamerica/coronavirus-brasil-supera-los-50-000muertos-509632

BUCKLAND, H., \& MURILLO, D. (2014). La innovación social en América Latina. Marco conceptual y agentes. Instituto de Innovación social. ESADE. Recuperado en http://idbdocs. iadb. org/wsdocs/getDocument.aspx

CEPAL. (2019). Panorama Social de América Latina 2019. Santiago de Chile. 
CEPAL. (2020). América Latina y el Caribe: proyecciones de crecimiento 2020. Recuperado el 2 de julio de 2020, de https://www.cepal.org/sites/default/files/pr/files/tabla_prensa_ proyecciones_pib-2020-esp.pdf

COMISIÓN EUROPEA. (2013). Guide to social innovation.

Recuperado de https://ec.europa.eu/eip/ageing/library/guidesocial-innovation_en

CORONAVIRUS EN BRASIL: 7 errores que llevaron a Brasil a la crítica situación actual. (18 de mayo de 2020) BBC News Mundo. Recuperado de https://www.bbc.com/mundo/noticiasamerica-latina-52708003

CORONAVIRUS: Brasil confirma el primer caso en América Latina. (26 de febrero de 2020). BBC News Mundo. Recuperado de: https://www.bbc.com/mundo/noticias-america-latina-51641436

COVID-19 en Colombia: medidas tomadas por el Gobierno. (9 de julio de 2020). Actualisece. Recuperado de https://actualicese. com/covid-19-en-colombia-medidas-tomadas-por-el-gobierno/

CRUZ-HOYOS, S. (31 de mayo de 2020a). De una botella de plástico a una mascarilla contra el Covid-19, el ingenioso diseño de un caleño. El País. Recuperado de https://www.elpais.com. co/elpaispalante/de-una-botella-de-plastico-a-una-mascarillacontra-el-covid-19-el-ingenioso-diseno-de-un-caleno.html

CRUZ-HOYOS, S. (31 de mayo de 2020b). En Cali, la solidaridad se cocina en 243 ollas comunitarias. El País. Recuperado de https://www.elpais.com.co/elpaispalante/en-cali-la-solidaridadse-cocina-en-243-ollas-comunitarias.html\#: - :text=En $\% 20$ cada $\% 20$ olla $\% 20$ comunitaria $\% 20$ hay,comida $\% 20$ en $\% 20$ d\%C3\%ADas\%20de\%20pandemia.

CUATRO LÍDERES SOCIALES que son luz de esperanza durante la crisis del Covid-19. (17 de mayo de 2020). El País. Recuperado de https://www.elpais.com.co/elpaispalante/cuatrolideres-sociales-que-son-luz-de-esperanza-durante-la-crisis-delcovid-19.html

DANE. (2020A). Empleo informal y seguridad social. Recuperado el 28 de junio de 2020, de https://www.dane.gov.co/index. 
php/estadisticas-por-tema/mercado-laboral/empleo-informal-yseguridad-social2020

DANE. (2020b). Estadísticas vitales nacimientos y defunciones: información I trimestre de 2020 y aculumado 2019.

Recuperado de https://www.dane.gov.co/index.php/estadisticaspor-tema/salud/nacimientos-y-defunciones

DECRETO 531 (8 de abril de 2020) "Por el cual se imparten instrucciones en virtud de la emergencia sanitaria generada por la pandemia del Coronavirus COVID-19, y el mantenimiento del orden público". Ministerio del Interior de la Republica de Colombia. Recuperado de https://dapre.presidencia.gov.co/ normativa/normativa/DECRETO 531 DEL 8 DE ABRIL DE 2020.pdf

DECRETO NO. 457 (2020) "Por el cual se imparten instrucciones en virtud de la emergencia sanitaria generada por la pandemia del Coronavirus COVID-19 y el mantenimiento del orden público”. Diario oficial. AÑO CLV. N. 51264. 22, MARZO, 2020. Presidencia de la Repiblica de Colombia. Recuperado de http://www.suin-juriscol.gov.co/viewDocument. asp? ruta $=$ Decretos $/ 30038972$

DECRETO NO. 493 (24 de abril de 2020) "Por el cual se adicionan los Decretos 1068 de 2015, Decreto Único Reglamentario del Sector Hacienda y Crédito Público, y 1077 de 2015, Decreto Único Reglamentario del Sector de Vivienda, Ciudad y Territorio, en lo relacionado con la adopción de disposiciones transitorias en materia de causales de terminación anticipada de la cobertura de tasa de interés otorgada a deudores de crédito de vivienda y locatarios en operaciones de leasing habitacional". Presidencia de la Republica de Colombia. Recuperado de https://www.funcionpublica.gov.co/eva/gestornormativo/norma. php?i=111176

DECRETO NO. 636 (6 de mayo de 2020) "Por el cual se imparten instrucciones en virtud de la emergencia sanitaria generada por la pandemia del Coronavirus COVID-19, y el mantenimiento del orden público". Presidencia de la Republica de Colombia. 
Recuperado de https://www.funcionpublica.gov.co/eva/ gestornormativo/norma.php?i=119997\#: - :text=8\%20del\%20 6\%20de\%20abril,en\%20las\%20Directivas\%2002\%2C\%2004 DECRETO NO. 689 (22 de mayo de 2020) "Por el cual se prorroga la vigencia del Decreto 636 del 6 de mayo de 2020 "por el cual se imparten instrucciones en virtud de la emergencia sanitaria generada por la pandemia del Coronavirus COVID-19, y el mantenimiento del orden público"”. Presidencia de la Republica de Colombia. Recuperado de https://www.funcionpublica.gov. co/eva/gestornormativo/norma.php?i=124943

DECRETO NO. 749 (28 de mayo de 2020) " "Por el cual se imparten instrucciones en virtud de la emergencia sanitaria generada por la pandemia del Coronavirus COVID-19, y el mantenimiento del orden público". Presidencia de la Republica de Colombia. Recuperado de https://dapre.presidencia.gov. co/normativa/normativa/DECRETO\%20749\%20DEL\%20 28\%20DE\%20MAYO\%20DE\%202020.pdf

DISENAN CABINAS para que personal médico se cambie sin contaminar. (7 de mayo de 2020). Agencias de noticias UNAL. Recuperado de http://agenciadenoticias.unal.edu.co/detalle/ article/disenan-cabinas-para-que-personal-medico-se-cambiesin-contaminar.html

DRABLE, L. (30 de mayo de 2020). Jair Bolsonaro let Coronavirus ravage Brazil. A Favela is taking matters into its own hands. The Intercept. Recuperado de https://theintercept.com/2020/05/30/ brazil-coronavirus-favela-mutual-aid/

EDMISTON, D. (2015). The UK social innovation policy agenda. CRESSI. Working Paper Series No. 19/2015. Oxford: University of Oxford.

EN BARRIOS PERIFÉRICOS de Medellín sacan trapos rojos para pedir ayudas. (13 de abril de 2020). H12N. Recuperado de https://h13n.com/en-barrios-perifericos-de-medellin-sacantrapos-rojos-para-pedir-ayudas/

EN SANTA MARTA fabrican dispensador de gel antibacterial con materiales de construcción. (27 de mayo de 2020). Seguimiento. 
Recuperado de https://seguimiento.co/la-samaria/en-santamarta-fabrican-dispensador-de-gel-antibacterial-con-materialesde-construccion

ESCOLAS DE SAMBA do Rio ajudam na produção de capotes descartáveis. (6 de abril de 2020). Gazeta Diigital. Recuperado de https://www.gazetadigital.com.br/variedades/variedades/ escolas-de-samba-do-rio-ajudam-na-produo-de-capotesdescartveis/612509

FÁBRICA DO SAMBA produz máscaras para doação à Prefeitura. (15 de abril de 2020). Cidade de São Paulo Saúde. Recuperado de https://www.prefeitura.sp.gov.br/cidade/secretarias/saude/ noticias $/$ p $=296232$

FUNDACIÓN COTEC para la innovación. (2017). La innovacion social en España. En Informe COTEC 2017 p.132. Recuperado de https://cotec.es/media/INFORME-COTEC-2017_ versionweb.pdf

GARCÍA-ALTAMAR, F. (25 de abril de 2020). Pobres invisibles: ¿Quiénes son y en dónde están? El Espectador. Recuperado de https://www.elespectador.com/noticias/bogota/pobres-invisiblesquienes-son-y-en-donde-estan-articulo-916465/

HERNÁNDEZ, R. (18 de abril de 2020). El trapo rojo que se convirtió en símbolo de auxilio. Radio Nacional. Recuperado de https://www.radionacional.co/noticias/actualidad/coronavirustrapos-rojos-comunidades

INGENIERÍA SIN FRONTERAS. (s.f.). La Gestión Comunitaria como Concepto. Recuperado el 1 de julio de 2020, de Construmática website: https://www.construmatica.com/ construpedia/La_Gestión_Comunitaria_como_Concepto

INSTITUTO NACIONAL DE SALUD. (2020). Covid-19

Colombia. Recuperado el 27 de junio de 2020, de Casos website: https://www.ins.gov.co/Noticias/Paginas/Coronavirus. aspx

LANGLOIS, J. ( de mayo de 2020). Las favelas de São Paulo se están quedando sin comida. Estas mujeres están interviniendo. National Geographic. Recuperado de https://www. 
nationalgeographic.com/science/2020/05/coronavirus-brazilsao-paulo-favelas-running-out-of-food-women-stepping-in/ LISSARDY, G. . (6 de febrero de 2020). Por qué América Latina es "la región más desigual del planeta". BBC News Mundo. Recuperado de https:/www.bbc.com/mundo/noticias-americalatina-51390621

MASCARILLAS A RITMO de samba (3 de junio de 2020). DW Noticias. Recuperado de https://www.dw.com/es/mascarillas-aritmo-de-samba/av-53675189

MELGAREJO, C. (19 de abril de 2020). La historia de los trapos rojos, un llamado para dar la mano. El Tiempo. Recuperado de https:/www.eltiempo.com/bogota/la-historia-de-los-traposrojos-un-llamado-para-dar-la-mano-486038

MENESES-SÁNCHEZ, C. (8 de abril de 2020). Así se organizaron las favelas en Brasil para sobrevivir a la pandemia. El Espectador. Recuperado de https://www.elespectador.com/coronavirus/asise-organizaron-las-favelas-en-brasil-para-sobrevivir-la-pandemiaarticulo-913597/

MINISTÉRIO DA ECONOMIA. (2020). Boletim das medidas tomadas em função da Covid-19 (Coronavírus). Recuperado el 30 de junio de 2020, de Governo Federal website: https:// www.gov.br/economia/pt-br/centrais-de-conteudo/publicacoes/ boletins/covid-19?b_start:int $=60$

MINISTÉRIO DA SAÚDE (2020). Coronavirus/Brasil. Recuperado el 30 de junio de 2020, de Ministério da Saúde website: https:// covid.saude.gov.br/

MINISTERIO DE SALUD y Protección Social. (2020). Lineamientos, Orientaciones y Protocolos para enfrentar la COVID-19 en Colombia. Recuperado de https://www. minsalud.gov.co/sites/rid/Lists/BibliotecaDigital/RIDE/VS/ lineamientos-orientaciones-protocolos-covid19-compressed.pdf MINISTERIO DE SALUD. (2020). Boletin 046: Colombia confirma su primer caso de COVID-19. Bogotá: Colombia. MORENO, M. (21 de Julio de 2020). Estos son los "pico y cédula" que rigen en Colombia durante cuarentena. El Tiempo. 
Recuperado de https://www.eltiempo.com/colombia/otrasciudades/pico-y-cedula-pico-y-genero-conozca-la-restriccion-encada-ciudad-de-colombia-484516

MOULAERT, F., MARTINELLI, F., SWYNGEDOUW, E., \& GONZÁLEZ, S. (2005). Towards Alternative Model ( $s$ ) of Local Innovation. Urban Studies, 42(11), 1969-1990. https:// doi.org/10.1080=00420980500279893

MULGAN, G. (2006). The process of social innovation. Innovations: Technology, Governance, Globalization, 1(2), 145-162. https:// doi.org/10.1162/itgg.2006.1.2.145

MUMFORD, M. D. (2002). Social Innovation: Ten Cases From Benjamin Franklin. Creativity Research Journal, 14(2), 253266. https://doi.org/10.1207/S15326934CRJ1402_11

NOGUERA-MONTOYA, S. P. (7 de abril de 2020). Escuelas de samba en Río de Janeiro ayudan a confeccionar capas para personal sanitario. AA. Recuperado de https:/www.aa.com. tr/es/mundo/escuelas-de-samba-en-r\%C3\%ADo-de-janeiroayudan-a-confeccionar-capas-para-personal-sanitario/1795051

PAIVA, P. (7 de abril de 2020a). Paraisópolis contrata médicos e ambulâncias, distribui mais de mil marmitas por dia e se une contra o coronavírus. Globo. Recuperado de https://g1.globo. $\mathrm{com} / \mathrm{sp} / \mathrm{sao}-$ paulo/noticia/2020/04/07/paraisopolis-se-unecontra-o-coronavirus-contrata-ambulancias-medicos-e-distribuimais-de-mil-marmitas-por-dia.ghtml

PAIVA, P. (29 de abril de 2020b). Escolas de Paraisópolis transformadas em áreas de isolamento para Covid-19 começam a receber contaminados. Globo. Recuperado de https:// g1.globo.com/sp/sao-paulo/noticia/2020/04/29/escolas-deparaisopolis-transformadas-em-areas-de-isolamento-para-covid19-comecam-a-receber-contaminados.ghtml PATON-WALSH, N., SHELLEY, J., BONNETT, W., \& FORTUNA, R. (14 de junio de 2020). Los carteles de Río de Janeiro pasan de traficar drogas ilícitas a proveer medicamentos. CNN en Español. Recuperado de https://cnnespanol.cnn. com/2020/06/14/los-carteles-de-rio-de-janeiro-pasan-de- 
traficar-drogas-ilicitas-a-proveer-medicamentos/ PÉREZ-DÍAZ, A. . (2016). Teoría y práctica del desarrollo comunitario. Un estudio de caso en un fraccionamiento de Ciudad Juárez, Chihuahua (México). Revista Iberoamericana para la Investigación y el Desarrollo Educativo, 6(12), 529-553. PHILLS, J. A., DEIGLMMEIES, K., \& MILLER, D. T. (2008). Rediscovering Social innovation. Stanford Social Innovation Review, 6(4), 34-43.

PRESIDENCIA DEL CONSEJO de Ministros de Perú. (2013).

Programa especial de soporte de CTI en transferencia y extensión tecnológica para la inclusión social y alivio de la pobreza (programa especial de innovación social). La Molina. PRIMERA MUERTE por coronavirus en Brasil: un paciente de 62 años falleció en San Pablo. (17 de marzo de 2020). Infobae. Recuperado de https:/www.infobae.com/america/americalatina/2020/03/17/primera-muerte-por-coronavirus-en-brasilun-paciente-de-62-anos-fallecio-en-san-pablo/

QUINTERO, F. L. (9 de junio de 2020). Pandemia desnudó la pobreza oculta en 'barrios ricos' de Bucaramanga. El Tiempo. Recuperado de https://www.eltiempo.com/colombia/santander/ pandemia-desnudo-pobreza-oculta-en-barrios-ricos-debucaramanga-504612

RESPIRADORES ARTIFICIALES nacionales están listos para salvar las vidas de pacientes con covid-19. (28 de junio de 2020). Noticias RCN. Recuperado de https://noticias.canalrcn. $\mathrm{com} /$ nacional/mujeres-de-ataque-con-juan-lozano-karenabudinen-359135

ROCHA, J. (21 de octubre de 2020). paraisópolis. Comunicación personal. San Pablo, Brasil.

RODRIGUES, D., Y BILLER, D. (7 de abril de 2020). Escuelas de samba de Río cosen mascarillas para coronavirus. The San Diego Union-Tribune. Recuperado de https:// www.sandiegouniontribune.com/en-espanol/noticias/ story/2020-04-07/escuelas-de-samba-de-rio-cosen-mascarillaspara-coronavirus 
SARDUY, M. I. R., \& CAMPOS, M. R. M. (2014). Comunidad y desarrollo comunitario: aspectos teóricos y metodológicos. Estudios del Desarrollo Social: Cuba y América Latina, 2(2), 77-89.

SIMS, S. (2 de mayo de 2020). How One of Brazil's Largest Favelas Confronts Coronavirus. Bloomberg. Recuperado de https:// www.bloomberg.com/news/features/2020-05-03/how-one-ofbrazil-s-largest-favelas-confronts-coronavirus

TIROS AL AIRE y rumba en una casa con el "trapito rojo" en Cali. (11 de mayo de 2020). Tu Barco. Recuperado de https:// tubarco.news/tubarco-noticias-occidente/tubarco-noticias-cali/ tiros-al-aire-y-rumba-en-una-casa-con-el-trapito-rojo-en-cali/ TORRES, M. R. M., MORALES, O. T., \& VARGAS, L. D. (2011). Caracterización de la pobreza oculta y su efecto en la sostenibilidad económica de las pequeñas y medianas empresas de la localidad de Usaquén (Bogotá-Colombia). Revista Facultad de Ciencias Económicas, 19(2), 123-140.

TUNUBALA, G. A. (2020). Ollas comunitarias en Cali. Comunicación personal.

UN LAVAMANOS PORTÁTIL para enfrentar la pandemia. (20 de abril de2020). Agencia de noticias Univalle. Recuperado de https:/www.univalle.edu.co/ciencia-y-tecnologia/lavamanosportatil-para-enfrentar-pandemia

UNA FIESTA de más de 500 personas fue descubierta en el oriente de Cali. (22 de junio de 2020). El País. Recuperado de https:// www.elpais.com.co/cali/una-fiesta-de-mas-de-500-personas-fuedescubierta-en-el-oriente-de-cali.html

UNAL produce gel antibacterial por la emergencia sanitaria. (20 de marzo de 2020). Agencia de noticias UNAL. Recuperado de https://agenciadenoticias.unal.edu.co/detalle/article/unalproduce-gel-antibacterial-por-la-emergencia-sanitaria.html UNIDOS DE PADRE MIGUEL oferece atendimento médico e máscaras para a comunidade. (16 de mayo de 2020). Globo. Recuperado de https:/g1.globo.com/rj/rio-de-janeiro/ noticia/2020/05/16/unidos-de-padre-miguel-oferece- 
atendimento-medico-e-mascaras-para-a-comunidade.ghtml

VOORBERG, W. H., BEKKERS, V., \& TUMMERS, L. (2013).

Co-creation and Co-production in Social Innovation: A

Systematic Review and Future Research Agenda. Lipse.Org, 320090(320090).

VOORBERG, W. H., BEKKERS, V., \& TUMMERS, L. (2014).

A Systematic Review of Co-Creation and Co-Production:

Embarking on the social innovation journey. Public

Management Review, 9037(July 2014), 1-25. https://doi.org/1

$0.1080 / 14719037.2014 .930505$

Notas de Página

${ }^{1}$ Varias iniciativas de las Universidades Colombianas para enfrentar el COVID-19 han sido recopiladas por Ascún https://ascun.org. $\mathrm{co} /$ noticias/detalle/iniciativas-de-nuestras-ies-asociadas-ante-elcovid-19.

Fecha de Recepción del Artículo: 30 de junio de 2020

Fecha de Aceptación: 10 de julio de 2020

Versión Final: 15 de julio de 2020 